\title{
Kajian analisis biaya dan manfaat (cost-benefit analysis) kawasan agrowisata di Indonesia
}

\author{
Study of cost-benefit analysis of agrotourism area in Indonesia \\ I Gusti Bagus Ananta Wijaya Putra ${ }^{1)^{*}}$, Agung Prijanto ${ }^{1)}$, Ni Made Classia Sukendar ${ }^{1)}$, \\ Gede Mekse Korri Arisena ${ }^{1)}$ \\ ${ }^{1}$ Fakultas Pertanian, Universitas Udayana, Bali, Indonesia \\ *Email korespondensi: anantawijaya170@gmail.com
}

Informasi artikel: Dikirim: 29/03/2020 Ditinjau: 29/03/2020 Disetujui: 01/09/2020

Copyright (c) 2020

I Gusti Bagus Ananta Wijaya Putra, Agung Prijanto, Ni Made Classia Sukendar Gede Mekse Korri Arisena
ABSTRACT: This study aims to compare financial feasibility studies on several agrotourism in Indonesia. The study about financial feasibility needs to be done as a material consideration in making a business decision. The method used a literature study for secondary data collection from several journals including NPV, IRR and Net B/C Ratio. This study reviews five agrotourism, that relates with cost-benefit analysis, including Kebun Buah Mangunan agrotourism, Kampung Budaya Sidangbarang agrotourism, Bukit Ganjau agrotourism, Bina Darma agrotourism, and Jamu Ramuan Madura agrotourism. The results of this study were obtained at Jamu Ramuan Madura agrotourism that was the most feasible with an NPV value of Rp. 13,979,701,973.49, - IRR of 30.52\%, and Net $B / C$ Ratio of 10.22 which indicated this agrotourism was feasible to run. This agrotourism is the most feasible because it has the highest value among the five other agrotourism. Kampung Budaya Sidangbarang agrotourism is the lowest feasibility level because it has an NPV value of Rp. 597,264,637.59, - with a Net $B / C$ value of 1.60 and an IRR of $15.13 \%$. Based on this, it is expected that the results of this study can become a reference for tourism developers to see the potential of agrotourism in areas that have the best financial viability.

Keywords: Cost-benefit analysis, agrotourism, financial feasibility

\begin{abstract}
ABSTRAK: Tujuan dari kajian ini adalah untuk membandingkan studi kelayakan finansial pada beberapa agrowisata di Indonesia. Kajian mengenai kelayakan finansial perlu dilakukan sebagai bahan pertimbangan dalam pengambilan keputusan suatu usaha. Metode yang digunakan adalah studi literatur untuk pengambilan data sekunder dari beberapa jurnal yang meliputi NPV, IRR dan Net $B / C$ Ratio. Kajian ini mereview lima agrowisata yang masing-masing berkaitan dengan analisis biaya manfaat diantaranya Agrowisata Kebun Buah Mangunan, Agrowisata Kampung Budaya Sindangbarang, Agrowisata Bukit Ganjau, Agrowisata Bina Darma dan Agrowisata Jamu Ramuan. Hasil dari kajian ini didapat pada agrowisata Jamu Ramuan Madura dikatakan paling layak dengan nilai NPV Rp 13.979.701.973,49,--, IRR sebesar 30,52\%, dan Net B/C Ratio sebesar 10,22 yang mengindikasikan Agrowisata ini layak untuk dijalankan. Agrowisata ini dikatakan paling layak karena memiliki nilai yang paling tinggi diantara kelima agrowisata lainnya. Adapun Agrowisata Kampung Budaya Sidangbarang merupakan agrowisata dengan tingkat kelayakan yang paling rendah karena memiliki nilai NPV sebesar Rp 597.264.637,59,--, dengan nilai Net B/C sebesar 1,60 dan IRR sebesar 15,13\%. Berdasarkan hal tersebut, diharapkan hasil kajian ini dapat menjadi acuan kepada pengembang pariwisata untuk melihat potensi agrowisata di daerah yang memiliki kelayakan finansial yang terbaik.
\end{abstract}

Keywords: Analisis biaya dan manfaat, agrowisata, kelayakan finansial 


\section{PENDAHULUAN}

Indonesia mempunyai daya tarik wisata meliputi antara lain wisata bahari dan wisata budaya, wisata berbasis perkebunan mulai berkembang pesat, salah satu upaya yang diperlukan adalah mengembangkan agrowisata. Peranan sektor pariwisata nasional semakin penting sejalan dengan perkembangan dan kontribusi melalui penerimaan devisa, pendapatan daerah, pengembangan wilayah, maupun dalam penyerapan investasi dan tenaga kerja serta pengembangan usaha yang tersebar di berbagai pelosok wilayah di Indonesia. Menurut BPS (2019), kontribusi sektor pariwisata terhadap Produk Domestik Bruto (PDB) nasional pada tahun 2017 telah mencapai 4,11 \%. Sementara devisa dari sektor pariwisata pada tahun 2014 telah mencapai Rp 120 triliun dan kontribusi terhadap kesempatan kerja sebesar 11 juta orang (Kholiq \& Parangu, 2020). Melalui mekanisme tarikan dan dorongan terhadap sektor ekonomi lain yang terkait dengan sektor pariwisata, seperti hotel dan restoran, angkutan, industri kerajinan dan lain-lain. Berdasarkan data terakhir dari Kemenparekraf (2015), disebutkan bahwa jumlah penerimaan pariwisata dari wisatawan mancanegara (wisman) ke Indonesia pada akhir periode 2009-2014 adalah sebesar US\$ 11.166,13 juta.

Sutjipta (2001, dalam Utama \& Junaedi, 2019), mendefinisikan bahwa agrowisata adalah sebuah sistem kegiatan yang terpadu dan terkoordinasi untuk pengembangan pariwisata sekaligus pertanian, dalam kaitannya dengan pelestarian lingkungan, peningkatan kesejahteraan petani. Pengembangan agrowisata pada suatu kawasan tentunya akan memperhitungkan keuntungan dan manfaat bagi masyarakat daerah sekitar. Menurut Utama dan Junaedi (2019), pengembangan agrowisata pada gilirannya akan menciptakan lapangan pekerjaan, karena usaha ini dapat menyerap tenaga kerja dari masyarakat pedesaan, sehingga dapat menahan atau mengurangi arus urbanisasi yang semakin meningkat saat ini.

Analisis biaya dan manfaat atau yang dikenal sebagai Cost Benefit Analysis (CBA) menurut Siegel dan Shimp (1994) dalam Apriliya dkk. (2010) adalah cara untuk menentukan hasil yang menguntungkan dari sebuah alternatif akan cukup untuk dijadikan alasan dalam menentukan biaya pengambilan alternatif (Apriliya dkk., 2010; Söderqvist dkk., 2015). Adapun menurut Arvanitoyannis (2008, dalam Prasetyo \& Arifin, 2017), CBA adalah metodologi yang bertujuan untuk memilih proyek dan kebijakan yang efisien dalam hal penggunaan sumber daya. CBA merupakan teknik yang paling umum digunakan untuk menghitung biaya (cost) dan manfaat (benefit).

Terdapat beberapa metode yang digunakan dalam analisis biaya dan manfaat yaitu metode Net Present Value Method (NPV), Payback Period Method (PP), Net B/C Ratio dan 
Internal Rate of Return Method (IRR). Menurut Mahaputriana (2006), NPV digunakan dalam penilaian investasi karena nilai uang setiap tahun akan mengalami perubahan sehingga kita harus mengembalikan nilai uang di masa yang akan datang (future value) menjadi nilai uang sekarang (present value). NPV pun dapat dikatakan sebagai terjadinya perbedaan antara nilai aliran kas keluar yang tergabung dengan proyek investasi. Kriteria penilaian NPV yaitu, jika NPV >0, maka usulan proyek diterima, jika $\mathrm{NPV}<0$, maka usulan proyek ditolak, dan apabila NPV $=0$, nilai perusahaan tetap walau usulan proyek diterima atau ditolak (Rumiyanto dkk., 2017). Net B/C Ratio merupakan nilai manfaat yang bisa didapatkan dari proyek atau usaha setiap kita mengeluarkan biaya sebesar satu rupiah untuk usaha tersebut. Menurut Febriyan dkk. (2017), Net B/C Ratio dapat diartikan sebagai rasio antara manfaat bersih yang bernilai positif dengan manfaat bersih yang bernilai negatif. Dengan kata lain, manfaat bersih yang menguntungkan bisnis yang dihasilkan terhadap setiap satu satuan kerugian dari bisnis tersebut.

Menurut Kasmir dan Jakfar (2004), IRR merupakan alat untuk mengukur tingkat pengambilan interen. IRR juga bisa dikatakan sebagai batas maksimum dari tingkat diskonto (discount rate). Metode IRR diartikan pula sebagai metode peningkatan usulan investasi dengan berpatokan pada IRR dari aktiva bersangkutan, dimana IRR dihitung dengan menyamakan nilai sekarang dari arus kas masuk masa mendatang dengan nilai sekarang dari biaya investasi (Rumiyanto dkk., 2017). Kriteria penerimaan dalam IRR adalah membandingkan IRR sesungguhnya dengan IRR yang diminta, hal ini dikenal dengan batas (hurdle rate). Selajutnya diasumsikan tingkat pengembalian yang diminta sudah diketahui, jika IRR melebihi tingkat pengembalian yang diminta, maka kegiatan investasi akan diterima, jika tidak kegiatan investasi akan ditolak. Adapun payback period merupakan salah satu kriteria penilaian investasi yang berupa jangka watu yang diperlukan dalam pengembalian seluruh investasi atau bisa diartikan sebagai teknik penilaian terhadap jangka waktu (periode) pengembalian invetsasi suatu proyek atau usaha). Metode PP adalah metode yang menghitung periode yang diperlukan untuk dapat menutup kembali pengeluaran investasi dengan menggunakan arus kas bersih (Rumiyanto dkk., 2017).

Analisis sensitivitas kemudian dilakukan untuk mengukur kelayakan proyek bila terdapat perubahan pada penerimaan dan biaya. Berdasarkan nilai payback period, maka dilakukan analisis sensitivitas untuk mengukur kepekaan proyek terhadap perubahanperubahan harga output dan input. Jika nilai NPV $>0$, Net $B C R>1$, dan IRR $>i$, maka suatu proyek dianggap layak (Asti, Priyarsono \& Sahara, 2016). 
Studi kelayakan merupakan bahan mengumpulkan beberapa jurnal yang pertimbangan dalam pengambilan keputusan digunakan sebagai acuan dalam melaksanakan usaha, baik menolak atau menerima rencana usaha dan mempertahankan atau menghentikan usaha yang sudah ada (Ibrahim, 2009). Beragamnya model agrowisata di beberapa daerah Indonesia dipengaruhi oleh potensi daerah tersebut. Oleh karena itu, membandingkan analisis biaya dan manfaat dari beberapa agrowisata di Indonesia menjadi penting dilakukan untuk menginformasikan kelayakan agrowisata di beberapa daerah di Indonesia.

Kajian ini bertujuan untuk membandingkan studi kelayakan finansial pada beberapa agrowisata di Indonesia dengan mengetahui terlebih dahulu komponen analisis kelayakan finansial, meliputi Net Present Value (NPV), Payback Period Method (PP), Internal Rate of Return (IRR), Net B/C Ratio dan kemudian dilanjutkan dengan analisis sensitivitas di beberapa agrowisata tersebut. Kajian ini menarik untuk dilaksanakan berkaitan dengan agrowisata yang terus berkembang di Indonesia. Kajian ini pun penting untuk dilaksanakan guna menjadi acuan kepada para pengembang pariwisata dalam melihat potensi agrowisata di daerah yang memiliki kelayakan finansial yang terbaik.

\section{METODE}

Kajian ini tidak mengumpulkan data dan acuan dalam menentukan apakah sebuah secara langsung, melainkan dengan usaha tani layak atau tidak. 


\section{HASIL DAN PEMBAHASAN}

Dalam pembangunan suatu proyek diperlukan analisis untuk mengetahui kelayakan (feasibility) proyek tersebut. Studi kelayakan suatu proyek diperlukan untuk meninjau apakah proyek tersebut layak dalam beberapa aspek, misalnya aspek teknis, aspek managerial dan administratif, aspek organisasi, aspek komersial, aspek ekonomi dan aspek finansial. Tidak semua proyek mencakup pertimbangan ke-lima aspek tersebut. Namun dalam pengambilan suatu keputusan investasi diperlukan pertimbangan terhadap aspek finansial. Dari sisi investor, investasi akan menarik apabila menguntungkan. Hal ini dapat dilihat dari berapa besarnya keuntungan atau profit yang akan didapat. Pertumbuhan ekonomi yang semakin berkembang dewasa ini dipicu oleh permintaan masyarakat akan adanya fasilitas penunjang ekonomi tersebut.

Pengembangan kawasan agrowisata dapat dijadikan alternatif solusi sebagai pemanfaatan fungsi ruang terbuka hijau yakni fungsi sosial budaya dan ekonomi, serta sebagai sarana edukasi melalui kegiatankegiatan yang menarik di dalamnya khususnya untuk anak-anak dan pelajar bahkan mampu memberikan dampak positif bagi daerah dan masyarakat disekitar kawasan pengembangan Agrowisata tersebut. Pengembangan agrowisata ini ada di lima agrowisata yang tersebar di beberapa daerah di Indonesia yang khususnya membahas mengenai analisis biaya manfaat. Agrowisata yang digunakan yaitu Agrowisata Kebun Buah Mangunan yang terletak di Kabupaten Bantul Yogyakarta, Agrowisata Kampung Budaya Sidangbarang yang terletak di Kecamatan Tamansari Kabupaten Bogor, Agrowisata Bukit Ganjau yang terletak di Kabupaten Kampar Provinsi Riau, Agrowisata Bina Darma yang terletak di Kabupaten Ogan Ilir Provinsi Sumatra Selatan, dan Agrowisata Jamu Ramuan Madura yang terletak di Kabupaten Sumenep.

Hasil kajian ini membandingkan beberapa agrowisata dengan memperlihatkan perbandingan dalam metode kajian sehingga dapat diberikan gambaran dengan beberapa agrowisata yang dalam kajian ini bisa bandingkan dengan hasil yang didapatkan beragam berdasarkan metodologi yang dipaparkan dari masing-masing jurnal. Metodologi kajian merupakan sebuah proses ilmiah berupa cara untuk memperoleh data yang dapat digunakan dalam kepentingan kajian ilmiah. Suatu metodologi adalah analisis teoritis tentang suatu metode Sedangkan kajian merupakan penyelidikan secara ilmiah dan sistematis dalam rangka mengembangkan pengetahuan. Kajian juga merupakan usaha yang sistematis dan terstruktur dalam menyelidiki suatu permasalahan yang membutuhkan jawaban yang ilmiah. Perbandingan metodologi kajian dari 5 jurnal dapat dilihat di tabel 1 sebagai berikut: 
Tabel 1. Perbandingan metodologi 5 agrowisata

\begin{tabular}{|c|c|c|c|}
\hline \multirow[b]{2}{*}{ Nama Agrowisata } & \multicolumn{3}{|c|}{ Metodologi Kajian } \\
\hline & $\begin{array}{c}\text { Metode } \\
\text { Pengambilan Sample } \\
\text { (sample ditulis } \\
\text { miring) }\end{array}$ & $\begin{array}{c}\text { Metode } \\
\text { Pengumpulan data }\end{array}$ & Analisa data \\
\hline $\begin{array}{c}\text { Agrowisata Jamu Ramuan } \\
\text { Madura }\end{array}$ & $\begin{array}{l}\text { Data primer dan data } \\
\text { sekunder }\end{array}$ & $\begin{array}{c}\text { Menekankan } \\
\text { keterlibatan } \\
\text { masyarakat secara } \\
\text { langsung, }\end{array}$ & $\begin{array}{c}\text { Metode NPV, Net } \\
\text { B/C dan IRR. }\end{array}$ \\
\hline $\begin{array}{l}\text { Agrowisata Kebun Buah } \\
\text { Mangunan }\end{array}$ & $\begin{array}{l}\text { Purposive sampling } \\
\text { dengan metode } \\
\text { judgement sampling. }\end{array}$ & $\begin{array}{c}\text { Observasi, } \\
\text { wawancara, } \\
\text { dokumentasi dan } \\
\text { studi pustaka }\end{array}$ & $\begin{array}{c}\text { Kelayakan } \\
\text { investasi } \\
\text { diantaranya NPV, } \\
\text { IRR dan Net B/C } \\
\text { Ratio }\end{array}$ \\
\hline Agrowisata Bukit Ganjau & $\begin{array}{l}\text { Data primer dan data } \\
\text { sekunder }\end{array}$ & $\begin{array}{c}\text { Segi aspek pasar, } \\
\text { aspek teknis, aspek } \\
\text { finansial dan analisis } \\
\text { sensitivitas. }\end{array}$ & $\begin{array}{l}\text { Aspek finansial } \\
\text { yaitu NPV, IRR } \\
\text { dan Net B/C } \\
\text { Ratio }\end{array}$ \\
\hline Agrowisata Bina Darma & $\begin{array}{l}\text { Data primer dan data } \\
\text { sekunder }\end{array}$ & $\begin{array}{l}\text { Metode wawancara } \\
\text { maupun kuesioner }\end{array}$ & $\begin{array}{l}\text { Net B/C Ratio, } \\
\text { NPVdan IRR }\end{array}$ \\
\hline $\begin{array}{l}\text { Agrowisata Kampung } \\
\text { Budaya Sidangbarang }\end{array}$ & $\begin{array}{l}\text { Analisis kualitatif dan } \\
\text { analisis kuantitatif }\end{array}$ & $\begin{array}{l}\text { Kelayakan investasi } \\
\text { dan analisis } \\
\text { sensitivitas dengan } \\
\text { metode switching } \\
\text { value. aspek non- } \\
\text { finansial yaitu aspek } \\
\text { pasar, aspek teknis, } \\
\text { aspek manajemen, } \\
\text { aspek hukum, dan } \\
\text { aspek sosial ekonomi } \\
\text { lingkungan }\end{array}$ & $\begin{array}{c}\text { Metode kriteria } \\
\text { kelayakan } \\
\text { investasi } \\
\text { menggunakan } \\
\text { NPV, IRR, Net B/C } \\
\text { Ratio. }\end{array}$ \\
\hline
\end{tabular}

Sumber data: Fatmawati (2013); Sofiana (2018); Mahaputriana (2006); Mulyana (2012) Nugroho (2010)

Berdasarkan tabel 1 di atas bahwa beberapa kajian agrowisata dari 5 jurnal di atas mengkombinasikan pengambilan data/sumber data pada data primer dan data sekunder sedangkan pada teknik pengambilan data bisa berbeda-beda tetapi pada analisa data tujuan ke 5 jurnal tersebut sama yaitu dengan metode kriteria kelayakan investasi menggunakan NPV, IRR dan Net B/C Ratio.
Analisis aspek finansial digunakan untuk menganalisis kelayakan usaha dari segi keuangan. Pada analisis aspek finansial ini digunakan beberapa kriteria investasi untuk mengukur kelayakan usaha yaitu Net Present Value (NPV), Internal Rate of Return (IRR), Net Benefit Cost Ratio (Net B/C). Kelayakan finansial, yang meliputi semua biaya yang dikeluarkan dan membandingkannya dengan 
semua manfaat yang diperoleh dalam bentuk investasi ini didasarkan pada besarnya manfaat aliran uang yang dikeluarkan maupun yang yang diterima dan biaya yang dikeluarkan diterima. Dalam hal ini semua biaya sesuai dalam menjalankan usaha agrowisata di dengan rencana dijadikan komponen biaya dan masing-masing jurnal dari 5 gambaran komponen manfaat diperoleh dari tarif atau agrowisata terletak pada tabel 2. harga barang/jasa investasi. Penilaian kriteria

Tabel 2. Perbandingan kelayakan finansial 5 agrowisata

\begin{tabular}{|c|c|c|c|c|c|}
\hline \multirow[b]{2}{*}{ Nama agrowisata } & \multirow[b]{2}{*}{ Notasi } & \multirow[b]{2}{*}{$\begin{array}{c}\text { Lama/umur } \\
\text { proyek }\end{array}$} & \multicolumn{3}{|l|}{ Nilai } \\
\hline & & & NPV & IRR & $\begin{array}{l}\text { Net } B / C \\
\text { ratio }\end{array}$ \\
\hline $\begin{array}{l}\text { Agrowisata Jamu Ramuan } \\
\text { Madura }\end{array}$ & $A g 1$ & 15 Tahun & Rp. 13.979.701.973,49 & $30,5 \%$ & 10,22 \\
\hline $\begin{array}{l}\text { Agrowisata Kebun Buah } \\
\text { Mangunan }\end{array}$ & Ag2 & 20 Tahun & Rp. 50.707.576.366,00 & $18,9 \%$ & 3,68 \\
\hline Agrowisata Bukit Ganjau & Ag3 & 15 Tahun & Rp. 3.861.131.859,00 & $19 \%$ & 1,68 \\
\hline Agrowisata Bina Darma & Ag4 & 14 Tahun & Rp.5.727.436.112,00 & $16 \%$ & 1,30 \\
\hline $\begin{array}{l}\text { Agrowisata Kampung } \\
\text { Budaya Sidangbarang }\end{array}$ & $\operatorname{Ag} 5$ & 10 Tahun & Rp. 597.264.637,59 & $15,1 \%$ & 1,60 \\
\hline
\end{tabular}

Sumber data: Fatmawati (2013); Sofiana (2018); Mahaputriana (2006); Mulyana (2012) Nugroho (2010)

Berdasarkan data yang diperoleh dari lima jenis agrowisata di beberapa daerah di Indonesia di dapat bahwa kelima jenis agrowisata ini layak untuk dikembangkan karena nilai Net B/C Ratio di masing-masing daerah tersebut lebih dari 1 . Nilai Net $\mathrm{B} / \mathrm{C}$ ratio terbesar berturut-turut yaitu $\mathrm{Ag} 1, \mathrm{Ag} 2, \mathrm{Ag} 3$, $\mathrm{Ag} 5$ dan Ag4 dengan nilai masing-masing senilai 10,$22 ; 3,68 ; 1,68 ; 1,60$ dan 1,30 .

Agrowisata dengan nilai NPV tertinggi terletak pada Agrowisata Kebun Buah Mangunan (Ag2) sebesar Rp. 50.707.576.366,00 sedangkan nilai IRR dan Net $B / C$ ratio tertinggi terletak pada Agrowisata Jamu Ramuan Madura (Ag1) senilai 30,52\% dan 10,22. Hal ini menunjukkan Agrowisata Kebun
Buah Mangunan memberikan penerimaan terbesar namun berdasarkan nilai Net B/C Ratio Agrowisata Jamu Ramuan Madura lebih layak dikembangkan dikarenakan dengan pengeluaran sebesar Rp 1 dihasilkan manfaat sebesar Rp 10,22, sedangkan agrowisata Kebun Buah Mangunan menghasilkan Rp 3,68 dari Rp 1 yang dikeluarkan. Dari perbandingan ini dapat dilihat bahwa Agrowisata Jamu Ramuan Madura lebih menguntungkan untuk dikembangkan oleh pengembang pariwisata dengan memanfaatkan potensi Jamu Ramuan Madura di Kabupaten Sumenep.

Perbandingan tingkat suku bunga pada agrowisata Jamu ramuan Madura dimana analisis kelayakan finansial pada usaha jasa 
agrowisata ini menggunakan tingkat suku bunga $12,4 \%$ yang merupakan tingkat suku bunga deposito Bank Indonesia per Januari 2013. Hal ini bisa dikuatkan dengan jurnal Cita, dkk. (2016), tentang Kelayakan perkebunan Jeruk di Kintamani bangli bahwa dengan tingkat suku bunga yang sama hasil dari perhitungan di atas dapat diketahui walaupun biaya investasi dalam usahatani jeruk siam mengalami peningktan sebesar $10 \%$, usahatani jeruk siam di Desa Sekaan, Kecamatan Kintamani Selatan, Kabupaten Bangli layak untuk dilanjutkan dan tidak terancam bangkrut karena waktu pengembalian modal investasi tetap lebih kecil darimasa umur proyek, nilai NPV masih bernilai positif, nilai net benefi/cost ratiodan gross benefi/cost rasio lebih besar dari 1, dan nilai IRR lebih besar daripada tingkat suku bunga yang berlaku di bank.

Agrowisata kebun buah Mangunan dengan tingkat bunga yang digunakan dalam analisis adalah tingkat bunga yang berlaku saat penelitian yaitu $12 \%$ yang merupakan tingkat suku bunga deposito bank pemerintah per Januari 2015. Hal ini diperkuat oleh jurnal dari Asti, dkk tahun 2016 dimana program Pengembangan Kawasan Pangan merupakan proyek investasi pada subsektor tanaman pangan dalam bentuk usaha kegiatan dengan budidaya skala besar (> 25 ha), terutama komoditas padi. Penelitian ini bertujuan untuk menganalisis kelayakan ekonomi Program Pengembangan Food Estate. Metode yang digunakan untuk menjawab penelitian tersebut adalah NPV, IRR, BCR, Pay Back Period dan analisis sensitivitas. Hasil penelitian menunjukkan bahwa NPV positif sebesar 153.761,83 miliar rupiah, IRR 63\%, BCR 1,25, Pay Back Period 8 tahun dan analisis sensitivitas peka terhadap perubahan harga input dan output. Dari pertimbangan di atas kriteria investasi, menunjukkan bahwa program tersebut layak secara ekonomi.

Agrowisata Bukit Ganjau tingkat bunga yang digunakan dalam analisis adalah tingkat bunga yang berlaku saat penelitian yaitu $10 \%$ yang merupakan tingkat suku bunga rata-rata tingkat suku bunga deposito bank umum selama satu tahun terakhir tahun 2006. Agrowisata yang serupa didapatkan di jurnal yang ditulis oleh dwitanti tahun 2013 tentang Analisa Manfaat Biaya Proyek Pembangunan Taman Hutan Raya (Tahura) Bunder Daerah Istimewa Yogyakarta dimana dalam penelitian ini dilakukan analisa manfaat dan biaya yang timbul akibat adanya proyek pembangunan Tahura Bunder yang dilaksanakan mulai tahun 2010. Metode yang digunakan adalah metode perbandingan manfaat dengan biaya (Benefit Cost Ratio). Metode ini membandingkan manfaat- manfaat yang ada dengan biaya-biaya yang dibutuhkan selama masa investasi 20 tahun dan suku bunga 10\%. Dari hasil analisa diperoleh nilai manfaat total $\mathrm{Rp}$. $30,540,241,864.33$ nilai kerugian total Rp. $3,209,360,830.06$ dan nilai biaya total Rp. 
18,843,225,774.21. Nilai BCR yang dihasilkan dari perbandingan manfaat dengan biaya adalah 1,70 memenuhi kelayakan.

Pada Agrowisata Bina Darma suku bunga dan Agrowisata Kampung Budaya Sidangbarang yang berlaku tingkat suku bunga yang dipakai pada akhir tahun 2009, yaitu sekitar 6,5\% (Bank Indonesia, 2010), suku bunga ini dijadikan acuan karena pembangunan obyek wisata agro. Hal ini didukung pada jurnal Ferdiansyah tahun 2010 dimana Aspek finansial dianalisis dengan menggunakan kriteria kelayakan investasi yaitu NPV, IRR, Net B/C, dan PBP. Nilai NPV yang diperoleh $\mathrm{Rp}$ 1.711.592.194,00,IRR 10 persen, Net B/C 1,20, dan PBP 8 tahun 2 bulan. Hasil tersebut menunjukkan bahwa secara finansial agrowisata markisa ini layak untuk dijalankan. Hasil analisis sensitivitas menunjukkan bahwa apabila skenario I dan skenario IV terjadi maka usaha taman agrowisata menjadi tidak layak untuk dijalankan. Sedangkan apabila skenario II, skenario III, dan skenario $\mathrm{V}$ terjadi maka usaha masih layak untuk dijalankan. Analisis nilai pengganti menggunakan skenario yang dianggap sensitif bagi proyek yaitu skenario I, skenario IV, dan skenario V. Berdasarkan analisis yang telah dilakukan maka disimpulkan bahwa dari segi aspek pasar, aspek teknis dan manajemen, dan aspek finansial usaha taman agrowisata ini layak untuk dijalankan.

Model pengembangan Agrowisata Jamu Ramuan Madura di Kabupaten Sumenep adalah pengembangan agrowisata yang berbasis masyarakat. Dengan begitu perkembangan agrowisata ini dapat meningkatkan pertumbuhan perekonomian Kabupaten Sumenep. Sejalan dengan penelitian yang dilakukan oleh Kader \& Soleman (2020), produksi pertanian yang dilakukan oleh masyarakat, dalam konteks agrowisata harus diberdayakan dan dikembangkan agar memberikan kontribusi positif dalam pemberdayaan ekonomi masyarakat. Jamu yang menjadi daya tarik wisata dari agrowisata ini tentu juga akan meningkatkan pendapatan dari sektor pertanian. Dengan begitu agrowisata ini juga dapat dirasakan oleh petani rempah-rempah sekitar daerah agrowisata. Pendapatan agrowisata ini bersumber dari penjualan karcis masuk dan karcis parkir dengan biaya yang keluar berupa biaya promosi sebesar $\operatorname{Rp} 10.000 .000,00$ setiap tahunnya kecuali pada tahun pertama yang besarnya dua kali dari biaya tersebut. Dari berbagai hasil penelitian menunjukkan agrowisata memberikan kontribusi yang positif bagi daerah dan masyarakat dengan bentuk riil adalah memberdayakan dan meningkatkan pendapatan masyarakat (Budiarti dkk., 2012; Herawati, dkk., 2014; Budiarti dkk., 2015; dan Cahyaningrum, 2017).

Kelayakan Ekonomi, yang meliputi semua biaya yang dikeluarkan baik tangible maupun intangible dan membandingkannya dengan semua manfaat yang diperoleh baik tangible 
maupun intangible. Dalam hal ini semua biaya sesuai dengan rencana dijadikan komponen biaya dan komponen manfaat diperoleh dari tarif atau harga barang atau jasa investasi (Giatman, 2006). Kelayakan ekonomi biasanya ditunjukkan oleh EIRR (economic internal rate of return) atau biasanya disebut juga IRR (internal rate of return). Dengan nilai IRR terbesar berturut-turut yaitu Ag1, Ag3, Ag2, Ag4 dan Ag5 dengan nilai masing-masing senilai $30,5 \%, 19 \%, 18,9 \%, 16 \%$ dan $15,1 \%$. Pada model pengembangan agrowisata Jamu Ramuan Madura didapatkan IRR yang terbesar. Berdasarkan kriteria IRR, diperoleh nilai IRR sebesar 30,52\%. Nilai IRR dari usaha ini ternyata melebihi nilai tingkat suku bunga atau discount factor yaitu $12,4 \%$, maka dapat disimpulkan bahwa usaha ini layak untuk dilaksanakan karena tingkat bunga maksimal yang dapat dibayar oleh proyek untuk sumber saya yang digunakan lebih besar daripada tingkat diskonto.

Analisis Sensitivitas dengan meneliti kembali suatu analisis untuk dapat melihat pengaruh-pengaruh yang akan terjadi akibat keadaan yang berubah-ubah disebut sebagai analisis sensitivitas, Gittinger (1986, dalam Asthutiirundu dan A. LAY, 2016). Pada sektor pertanian, proyek dapat berubah-ubah sebagai akibat dari empat permasalahan yaitu: 1) Perubahan harga jual produk 2) Keterlambatan pelaksanaan proyek 3) Kenaikan biaya 4) Perubahan volume produksi. Tujuan analisis sensitivitas adalah untuk melihat apa yang akan terjadi dengan hasil analisis proyek jika ada suatu kesalahan atau perubahan dalam dasardasar perhitungan biaya atau manfaat (Grant, 1996 dalam Yuliandri, M., 2014).

Analisis ini diperlukan sebab analisis proyek didasarkan pada proyeksi-proyeksi yang banyak mengandung ketidakpastian tentang apa yang akan terjadi di waktu akan datang. Hasil analisa sensitivitas pada ke lima jurnal dapat ditunjukkan di atas dimana nilai IRR > nilai suku bunga pada tahun tersebut dimana padan Jurnal Ag1 nilai IRR (30,5\%) > nilai suku bunga (12,4\%), jurnal Ag2 nilai IRR (19\%) > nilai suku bunga (12\%), Jurnal Ag3 nilai IRR $(18,9 \%)>$ nilai suku bunga (10\%), jurnal Ag3 nilai IRR $(16 \%)>$ nilai suku bunga $(6,5 \%)$ dan jurnal Ag4 nilai $\operatorname{IRR}(15,1 \%)>$ nilai suku bunga $(6,5 \%)$ sehingga didapatkan bahwa analisis sensitivitas ini dilakukan pada lima jurnal yang di-review menunjukkan bahwa adanya perbedaan analisa sensitivitas antara agrowisata bidang pertanian dengan agrowisata yang mengutamakan keindahan alam suatu kampung.

\section{KESIMPULAN}

Kajian ini membandingkan studi kelayakan finansial yang terdapat di lima daerah agrowisata di Indonesia di antaranya, Agrowisata Kebun Buah Mangunan, Agrowisata Kampung Budaya Sindangbarang, Agrowisata Bukit Ganjau, Agrowisata Bina Darma dan Agrowisata Jamu Ramuan dengan mengetahui 
komponen analisis kelayakan finansial yang meliputi NPV, IRR dan Net B/C Ratio. Nilai IRR dan Net $B / C$ Ratio tertinggi terletak pada Agrowisata Jamu Ramuan Madura (Ag1) senilai 30,52\% dan 10,22 dengan NPV sebesar Rp 13.979.701.973,49 dengan umur proyek selama 15 Tahun. Agrowisata Jamu Ramuan Madura merupakan agrowisata terlayak dari agrowisata lainnya dan patut dikembangkan dikarenakan dengan pengeluaran sebesar Rp 1 dihasilkan manfaat sebesar Rp 10,22. Diharapkan hasil kajian ini dapat menjadi acuan kepada pengembang pariwisata untuk melihat potensi agrowisata di daerah yang memiliki kelayakan finansial yang terbaik.

\section{SARAN}

Hasil kajian ini menunjukkan kelayakan Agrowisata Jamu Ramuan Madura sebagai yang terbaik. Bagi pihak terkait disarankan untuk lebih aktif mempromosikan Agrowisata tersebut lebih luas untuk menarik perhatian investor sehingga dapat meningkatkan pendapatan Agrowisata Jamu Ramuan Madura yang juga berdampak positif bagi kesejahteraan masyarakat sekitar daerah Agrowisata. Kajian lebih lanjut juga diperlukan untuk mengukur tingkat kunjungan kembali wisatawan ke Agrowisata Jamu Ramuan Madura.

\section{DAFTAR PUSTAKA}

Apriliya, F. C., Kartika, P. S., M. Rahadian., Pingky, S. R., Rahmadani, E. R., Taufik F., Viko Basmalah W., \& Wachid D. S. (2010).
Analisis kelayakan teknologi informasi menggunakan metode cost benefit analysis dengan microsoft excel. $J l, ~ 1(2)$. https://taufikfebrianto.files.wordpress.co $\mathrm{m} / 2013 / 07 /$ jurnal-cost-benefitanalysis.pdf

Asthutiirundu, \& Lay, A. (2016). Analisis kelayakan finansial pengolahan tepung sagu menjadi produk kue bagea (studi kasus pada industri rumah tangga di Minahasa Selatan). Buletin Palma, 14(1), 61-68. http://dx.doi.org/10.21082/bp. v14n1.2013.61-68

Asti, A., Priyarsono, D. S., \& Sahara. (2016). Analisis biaya dan manfaat program pembangunan food estate dalam perspektif perencanaan wilayah: studi kasus provinsi Kalimantan Barat. Jurnal Agribisnis Indonesia, 4(2), 79-90. https://doi.org/10.29244/jai.2016.4.2.7990

BPS. (2019). Proporsi kontribusi pariwisata terhadap PDB (persen). Badan Pusat Statistik.

Budiarti, T., \& Listyanti, A. D. (2015). Development of community-based Agrotourism on integrated farming system toward sustainable village. Australian Journal of Basic and Applied Sciences 9(7), 242-244. https://www.cabdirect.org/cabdirect/abs tract/20153219198

Budiarti, T., Makalew, A. D. N., Nasrullah, N., Saptana \& Haryati, U. (2012). Potential evaluation of community-based agritourism in Banyuroto and Ketep rural landscape Magelang Distric, Central Java, Indonesia. In Symposium IFLA Asia Pacific Shanghai (CN). Oct 23-25, 2012.

Cahyaningrum, D. (2017). Community empowerment based local wisdom in tourism of bajo community, Wakatobi. International Journal of Scientific and Technology Research 6(11), 196-201.

Cita, I. D. P. G. A., Sarjana, I. D. G. R., \& Rantau, I. K. (2016). Kelayakan finansial usaha perkebunan jeruk siam di Desa Sekaan Kecamatan Kintamani Selatan Kabupaten Bangli. Jurnal Agribisnis dan Agrowisata, 
5(4), 722-731. https://ojs.unud.ac.id/ index.php/JAA/article/view/24534

Fatmawati, I. (2013). Kelayakan agrowisata jamu ramuan madura di kabupaten Sumenep. Jurnal

Pertanian

Cemara, 10(1), 6-9. https://doi.org/10. 24929/fp.v10i1.29

Febriyan, H.Y., Walangitan, D.R., \& Sibi, M. (2017). Studi kelayakan proyek pembangunan perumahan bethsaida bitung oleh PT. cakrawala indah mandiri dengan kriteria investasi. Jurnal Sipil Statik, 5(7), 401-410. https://ejournal. unsrat.ac.id/index.php/jss/article/view/1 7121

Ferdiansyah, (2010). Analisis kelayakan finansial perencanaan agrowisata markisa di Kecamatan Tombolo Pao Kabupaten Gowa Propinsi Sulawesi Selatan [Thesis]. Departemen Agribisnis Fakultas Ekonomi dan Pembangunan Institute Pertanian Bogor (IPB) Bogor.

Giatman, M. (2006). Ekonomi teknik. Raja Grafindo Persada.

Herawati, A., Purwaningsih, A., Pudianti, A., \& Surya, R. V. (2014). Rural tourism community empowerment based on loacl resources for improving community welfare: case on Pentingsari Village, Yogyakarta, Indonesia. Review if Integrative Business and Economics Research, 3(2), 88-100. http://www. sibresearch.org/uploads/2/7/9/9/279922 7/riber_b14-071_88-100.pdf.

Ibrahim, Y. (2009). Studi kelayakan bisnis. Rineka Cipta.

Juliandi, Azuar, Irfan, \& Saprinal Manurung. (2014). Metode kajian bisnis konsep dan aplikasi. UMSU Press.

Kader, A., \& Soleman, S. (2020). Pemanfaatan kelayakan alam dan hasil pertanian sebagai modal pengembangan agrowisata daerah. Jurnal of Ethnic Diversity and Local Wisdom, 2(1), 17-27. http://jurnal. ummu.ac.id/index.php/jedilwisdom/articl e/view/451

Kasmir \& Jakfar. (2004). Studi kelayakan bisnis. Mizan Media Utama.
Kemenparekraf. (2015). Devisa (penerimaan) wisatawan mancanegara menurut negara tempat tinggal. Tersedia secara online: https://www.kemenparekraf.go.id/post/d evisa-penerimaan-wisatawanmancanegara-menurut-negara-tempattinggal

Kholiq, A., \& Parangu, K. A. (2020). Pengaruh Kualitas pelayanan dan pengemasan daya tarik wisata terhadap kepuasan wisatawan di Ngebel Ponorogo. Jurnal Sosiologi Reflektif, 14(2), 407-423. https://doi.org/10.14421/jsr.v14i2.1836

Mahaputriana. (2006). Analisis kelayakan finansial taman agrowisata bukit ganjau, kabupaten Kampar, provinsi Riau [Thesis]. Institut Pertanian Bogor. https://repository.ipb.ac.id/jspui/bitstrea m/123456789/50516/1/A06mah.pdf

Mulyana, E., Putri, E.I.K., \& Hadi, S. (2012). Analisis prakelayakan untuk mencapai wisata agro berkelanjutan: studi kasus agrowisata bina darma di kabupaten Ogan Ilir provinsi Sumatera Selatan. Jurnal Agripita, 1(4), 255-266. https://ejournal.unsri.ac.id/index.php/agr ipita/article/view/2042/852

Nugroho, A. (2010). Analisis kelayakan usaha agrowisata kampung budaya sidangbarang kecamatan Tamansari, kabupaten Bogor [Thesis]. Institut Pertanian Bogor. https://repository. ipb.ac.id/handle/123456789/60396

Prasetyo, A. \& Arifin, M. Z. (2017). Analisis biaya pengelolaan limbah makanan restoran. Indocamp.

Rumiyanto, R., Irwan, H. \& Purbasari, A. (2015). Analisa studi kelayakan penambahan mesin cnc baru dengan metode npv (net present value) di PT. usda seroja jaya shipyard Batam. Profisiensi, 3(2), 151-159. https://www.journal.unrika.ac.id/index.p hp/jurnalprofisiensi/article/view/336/306

Söderqvist, T., Brinkhoff, P., Norberg, T., Rosén, L., Back, P. E., \& Norrman, J. (2015). Costbenefit analysis as a part of sustainability assessment of remediation alternatives for contaminated land. Journal of environmental management, 157, 267- 
278. https://doi.org/10.1016/j.jenvman. 2015.04.024

Sofiana, A. T. (2018). Analisis kelayakan finansial agrowisata kebun buah (studi kasus di agrowisata kebun buah mangunan, Bantul, Yogyakarta). Jurnal Ilmiah Agritas, 1(2). http://www.jurnal. ustjogja.ac.id/index.php/agritas/article/vi ew/2879/1727

Sulaiman, S., \& Kushendrayana. (2013). Pengantar statistika: aplikasinya dalam bidang pariwisata, usaha perjalanan dan perhotelan. Alfabetha.

Utama, I. G. B. R., \& Junaedi, I. W. R. (2019). Agrowisata sebagai pariwisata alternatif indonesia: solusi masif pengentasan kemiskinan. Deepublish.
Utami, D. W., \& Indrayani, R. (2013). Analisa manfaat biaya proyek pembangunan taman hutan raya (tahura) bunder Daerah Istimewa Yogyakarta. Jurnal Teknik Pomits 2 (1), 17-21. http://dx.doi.org/ 10.12962/j23373539.v2i1.3101

Yuliandri, M. (2014). Analisa kelayakan pengembangan PT. wira simentrica [Thesis]. Universitas Islam Negeri Sultan Syarif Kasim Riau. http://repository.uinsuska.ac.id/3760/ 